\title{
There is more to recycled concrete aggregate than just aggregate
}

\author{
Z. A. Krezel ${ }^{1}$, K. J. McManus ${ }^{1}$, N. Cumbo ${ }^{1}$, H. Karlie ${ }^{1}$ \& C. Cox ${ }^{2}$ \\ ${ }^{1}$ Swinburne University of Technology, Hawthorn, Victoria, Australia \\ ${ }^{2}$ Delta Group, Concrete Recycling Division, Sunshine, Victoria, Australia
}

\begin{abstract}
In Australia, recycled concrete aggregate (RC Aggregate) is produced mainly from two sources, viz. crushed demolition waste concrete and relatively 'fresh' crushed construction waste concrete. Apart from standard fine and coarse particles, RC Aggregate consists of a significant amount of very fine dust intrinsic to the crushing process of concrete waste. The amount and characteristics of the very fine particles and presence of cement paste residue (CPR) differentiate RC Aggregate from commonly used crushed natural aggregate. The aggregate fines and CPR impact a number of basic engineering properties of the aggregate and also have potential to influence behaviour of the aggregate's varies applications, including road base and concrete.

This paper reports on an investigation into mineral composition and re-cementing potential of RC Aggregate. Scanning Electron Microscopy with Energy Dispersive X-ray analysis and the X-Ray Diffraction examination were used to determine elemental and compound composition of solid CPR and fines of the aggregate. The re-cementing potential of the fines was assessed by a method, commonly used in determination of cement content in cement treated aggregate used in roads construction.

The results indicate that mineral composition of RC Aggregate is different from that of natural crushed aggregate or commonly used fine concrete sand. Preliminary results also indicate that RC Aggregate contains some anhydrous materials that react with Portland or Blended cements, or undergo a pozzolanic reaction with some hydration products such as calcium hydroxide.
\end{abstract}

Keywords: recycled concrete aggregate, mineral composition, re-cementing. 


\section{Background}

The 2004 annual survey of Victorian recycling industries reports that recovery rate of construction and demolition (C\&D) waste has increased, and the amount of concrete waste recycled in the financial year 2004 has increased to $1.55 \mathrm{M}$ tonnes (Ecorecycle Victoria, [1]).

A significant contribution to the increased rate of waste recovery is attributed to an exemplary partnership between Delta Group Pty Ltd and Boral Resources Pty Ltd, resulting in an integrated approach to C\&D waste in the metropolitan Melbourne. The partnership aims at minimisation of waste generation, development of processes and procedures preventing waste contamination, and also at the maximisation of waste recovery and value added reuse of recycled products. This joint venture enables the two companies to achieve high environmental outcomes balanced with strong economic return. The production and sales of recycled construction materials, extends the life resource of existing quarries and reduces $C \& D$ waste in landfills.

The C\&D waste concrete and brick is sorted and crushed similar to standard hard rock quarry plants, with the addition of a detailed pre-crushing inspection and sorting process. During crushing with addition of several magnets, the steel is removed and recycled. Picking points on specially designed conveyors are utilised for the final removal of any deleterious materials. A wide range construction materials can be produced.

The recent redevelopment of the Melbourne Cricket Ground (MCG) is an excellent example of recycling C\&D waste. The massive amounts of concrete, brick and steel were processed at Delta's crushing and recycling plant at Sunshine, where products in accordance to VicRoads specifications were produced and supplied to the Tullamarine Freeway/ Bulla Road project, and the Royal Showground's redevelopment project (Vicroads, [2]).

In terms of concrete, the bulk of the waste comes to recycling plants from demolished structures, and this type of concrete is assumed to be fully hydrated. There is also a considerable amount of relatively fresh concrete waste from construction sites where over-specified or rejected concrete is deposited at recycling plant. The construction type of concrete waste is presumed to be not fully hydrated. However, both types are mixed in the crushing process, resulting in a wide range of concrete recycling products (RC Aggregate).

A common feature of all types of RC Aggregate is a presence of CPR which is in a form of solid particles or in a form of a powder, of very fine particles $(\leq 75 \mu \mathrm{m})$. The quality and quantity of the CPR influences significantly the basic engineering properties of RC Aggregate, including particle and bulk density, water absorption and aggregate reactivity. Krezel and McManus [3] state that typically RC Aggregate consists of $24 \%$ of cement paste residue and the fine content is approximately $2 \%$, which can have significant impact on behaviour of subbase layer in roads and concrete made from such aggregate.

Katz, [4] states that unique to RC Aggregate is the anhydrous nature of very fine particles, particularly that passing $75 \mu \mathrm{m}$ sieve, which can influence hydration of cement in new concrete. The hydration can be hindered by 
increased water consumption but at the same time can also be enhanced by recementing properties of very fine particles and presence of solid particles of cement paste residue.

This paper reports on a research project aiming at the investigation of the influence of cement paste residue on properties of new concrete and other applications of RC Aggregate. The focus of this paper is on mineralogical characterization of $\mathrm{CPR}$ and differentiation of $\mathrm{RC}$ Aggregate from basalt aggregate, which is the commonly used natural aggregate in concrete technology and road constructions, for the Melbourne and Victoria Region.

\section{Methodology}

RC Aggregate was segregated into solid and powder particles. The powder sample suite consisted of particles passing $75 \mu \mathrm{m}$ sieve. The mineral and elemental composition of the aggregate were investigated and compared with those of natural coarse aggregate and concrete sand.

Mineral composition was determined using X-ray Diffraction and supplemented with an examination of elemental composition using Scanning Electron Microscopy.

The potential of RC Aggregate to augment hydration of cement in new concrete or cement treated road base aggregate was examined using procedures of determining cement content in cement treated aggregate for subbase layers in road construction according to Australian Standard procedures (SAA, [5]).

\section{Scanning Electron Microscopy}

Scanning Electron Microscopy was used to investigate the differences in elemental composition between natural and RC Aggregate. Two types of aggregate; the fines of RC Aggregate and the fines of basalt aggregate were analysed and compared with General Blended (GB) cement.

Powder samples were obtained from the aggregate's fines and some were ground to powder from larger particles of CPR. Solid samples were either cut from RA Concrete into thin slabs $(20 \times 20 \times 2 \mathrm{~mm})$, or smaller particles were embedded in cold mounting resin. Representative areas of powder and solid samples were analysed using Energy Dispersive (ED) X-ray facilities to determine elemental composition. Figure 1 presents a typical Backscatter Electron (BSE) image of RC Aggregate fines.

In each of the powder samples that were examined, a number of representative areas were selected to analyse elemental composition. Figure 2 presents a graphic representation of the ED X-ray analysis results of one of the areas representing RC Aggregate fines.

The analysis of the BSE images of the RC Aggregate fines indicates relatively well-distributed particles of various sizes. The results of the ED analysis indicate that the two equally dominant elements present in RC Aggregate fines are silicon and calcium, with traces of other elements such as aluminum, iron, potassium, sulfur, magnesium, chloride, titanium and sodium. 


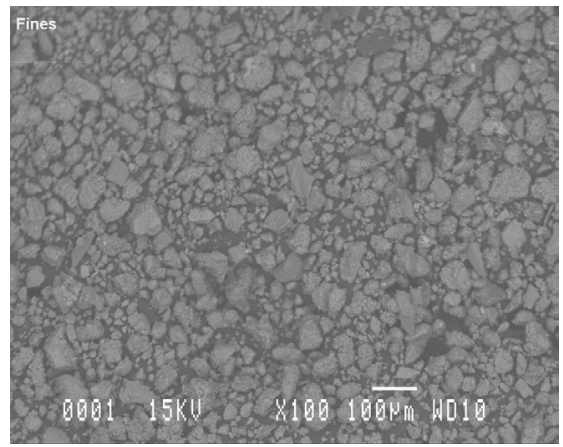

Figure 1: $\quad$ Typical BSE image of RC Aggregate fines.

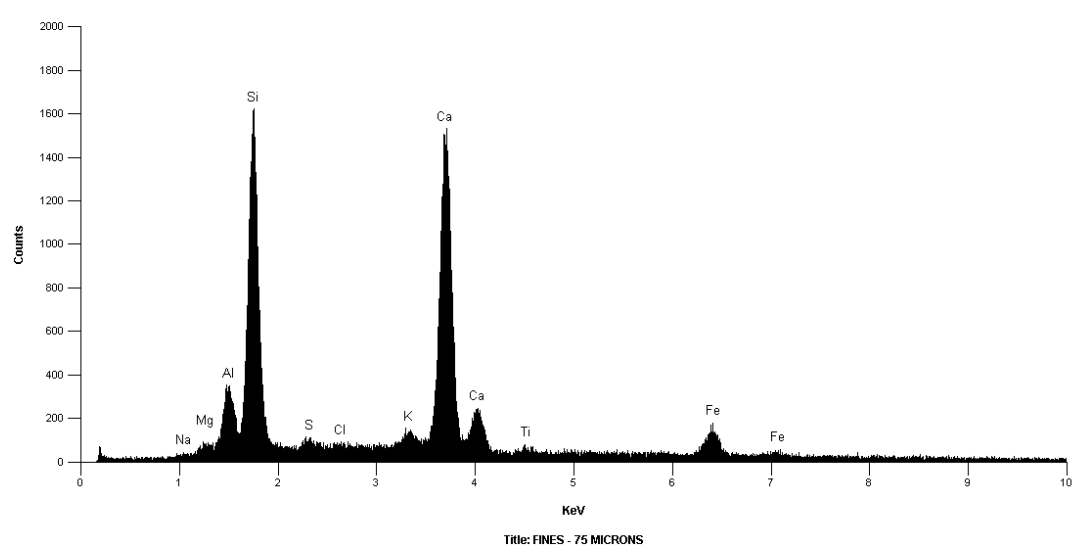

Figure 2: $\quad$ ED X-ray analysis of RC Aggregate fines.

Further, to enhance understanding of mineral characteristics of RC Aggregate fines, two similar materials were examined; fines of basaltic aggregate and GB cement. Figure 3 presents a typical example of a BSE image of fines of basalt aggregate, and Figure 4 shows the ED X-ray analysis of the basaltic fines passing a $75 \mu \mathrm{m}$ sieve.

It seems that the shape of particles of basaltic fines is generally elongated and angular which is different from round particles of RC Aggregate's fines. The difference in shape between the fine particles of natural and RC Aggregate can be attributed to lesser handling, and to the structural and mineral makeup of these aggregate. The round shape of the fines of RC Aggregate is presumed to be the result of excessive handling and presence of softer, calcium rich minerals. The ED X-ray analysis results indicate that basalt aggregate is silica rich aggregate consisting of $80 \%$ silica.

The analysis of BSE images of GB cement indicate that the predominant particle size is approximately $15 \mu \mathrm{m}$ which is significantly smaller than the very fine particles of RC Aggregate and basalt aggregate. The ED X-ray analysis of 
the GB shows that approximately $75 \%$ of the total content of the cement is calcium, in one of its oxide forms.

Solid samples of RC Aggregate were analysed using identical procedures and testing environment to that of the powder samples. Figure 5 shows a typical example of a BSE image of highly weathered cement paste residue.

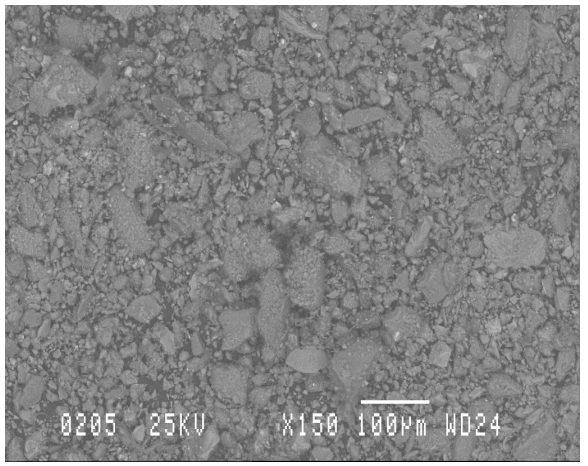

Figure 3: $\quad$ BSE image of natural aggregate (basalt) fines.

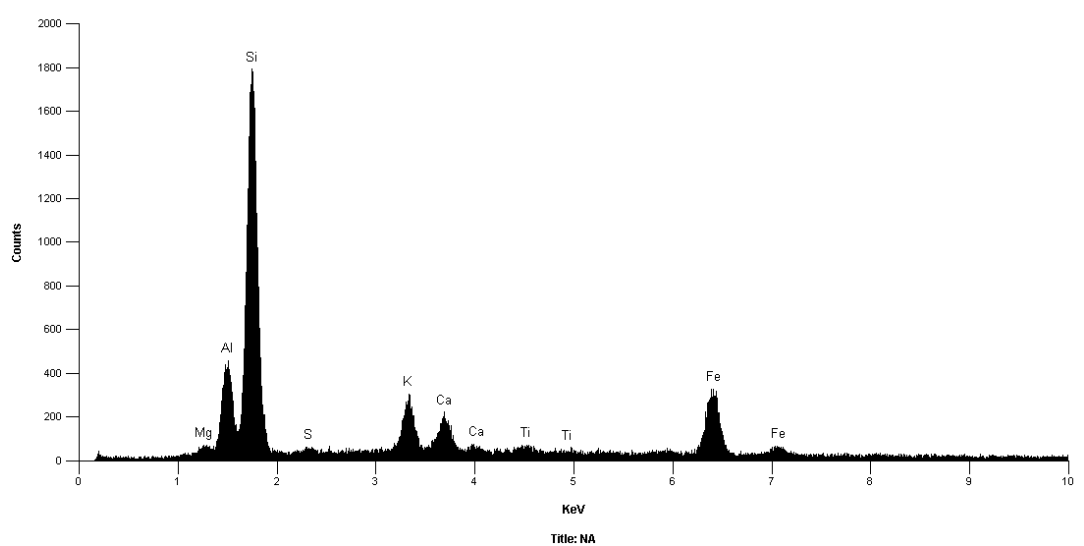

Figure 4: $\quad$ ED X-ray analysis of natural aggregate (basalt) fines.

Darker grey areas represent sand particles, lighter coloured areas represent hydrated cement paste, whereas very bright, almost white areas, are representative of metallic elements (typically minor inclusions of iron, titanium and magnesium). Table 1 shows a summary of an elemental composition of basalt (natural) aggregate and RC Aggregate (cpr powder and cpr solid).

The results indicate that despite a minor content of various elements including aluminum, potassium, sulfur, magnesium, chlorine, titanium and sodium the main elements in both natural and RC Aggregate are silica, calcium and iron. 
The significant content of calcium, silica, iron and aluminum in RC aggregate which is a result of cement paste residue presence and in service environmental conditions of concrete.

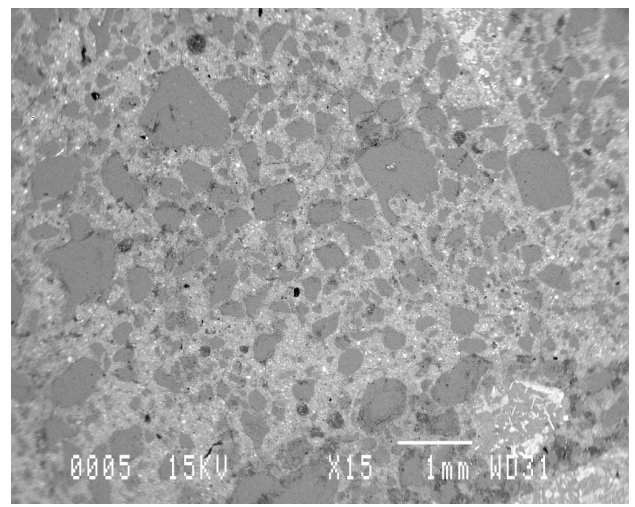

Figure 5: $\quad$ BSE image of typical cement paste residue solid sample.

Table 1: Average composition of dominant elements in natural and RC Aggregates.

\begin{tabular}{|c|c|c|c|c|}
\hline \multirow[t]{3}{*}{ Element } & \multirow{3}{*}{$\begin{array}{l}\text { In an oxide } \\
\text { form of }\end{array}$} & \multicolumn{3}{|c|}{ Elemental composition [\%] } \\
\hline & & \multirow{2}{*}{$\begin{array}{l}\text { Natural } \\
\text { aggregate }\end{array}$} & \multicolumn{2}{|c|}{ RC Aggregate } \\
\hline & & & solid & powder \\
\hline Silicon & $\mathrm{SiO}_{2}$ & 95.77 & 34.85 & 33.98 \\
\hline Calcium & $\mathrm{CaO}$ & 1.25 & 35.36 & 37.97 \\
\hline Iron & $\mathrm{Fe}_{2} \mathrm{O}_{3}$ & 0.00 & 18.78 & 18.17 \\
\hline Aluminum & $\mathrm{Al}_{2} \mathrm{O}_{3}$ & 0.72 & 5.60 & 5.24 \\
\hline Other & & 2.26 & 5.41 & 4.64 \\
\hline
\end{tabular}

\section{X-ray diffraction analysis (XRD)}

Further, the mineral composition of RC Aggregate was investigated using the X-Ray Diffraction method. The XRD technique is widely used to identify the qualitative and quantitative composition of different types of mineral compounds present in concrete aggregate. In the XRD examination, samples derived from concrete waste of original water-cement ratio of $0.2,0.4$ and 0.8 were tested. Table 2 presents examples of typical mineral composition of RC Aggregate cement paste residue and aggregate fines.

The dominant mineral in RC Aggregate is physically and chemically stable quartz, which also is a desirable mineral in concrete sand and other concrete aggregate. The recycled aggregate also consists of a significant amount of biotite and feldspars which are less stable and may result in a formation of deleterious clay minerals. In isolated cases, the XRD examination revealed the 
presence of a very small amount of montmorillonite which is a clay mineral. The differentiating mineral between basalt aggregate and RC Aggregate is shown by the presence of approximately $14 \%$ of calcite in recycled aggregate.

Table 2: $\quad$ Mineral composition of fine particles of RC Aggregate.

\begin{tabular}{|c|c|c|c|c|c|c|}
\hline \multirow{2}{*}{ Samples } & \multicolumn{7}{|c|}{ Mineral Compounds [\%] } \\
\cline { 2 - 7 } & $\begin{array}{c}\text { Quartz } \\
\text { (alpha } \\
\text { phase) }\end{array}$ & Calcite & $\begin{array}{c}\text { Biotite } \\
\text { (mica) }\end{array}$ & $\begin{array}{c}\text { Anorthite } \\
\text { (plagioclase } \\
\text { feldspar) }\end{array}$ & Albite & Forsterite \\
\hline $02-1$ & 37.4 & 8.2 & 23.8 & - & 30.2 & 5.2 \\
\hline $02-2$ & 41.6 & 11.3 & 2.2 & 18.9 & 15 & 11 \\
\hline $04-1$ & 58.7 & 22.3 & 3.7 & 7.3 & 8 & - \\
\hline $04-2$ & 53.6 & 20.1 & 5.7 & 20.6 & - & - \\
\hline $08-1$ & 73.1 & 7 & 1.1 & 18.9 & - & - \\
\hline $08-2$ & 46.2 & 10.5 & 10.6 & 17.7 & 15 & - \\
\hline
\end{tabular}

\section{Cement content in RC Aggregate}

For the purpose of determination of the re-cementing properties of RC Aggregate fines, test specimens of $2 \%$ of particles passing $75 \mu \mathrm{m}$ were prepared.

Two approaches were adopted to investigate the re-cementing potential of fines; firstly, substitution of GB cement with excessive ( $2 \%)$ amount of $\leq 75 \mu \mathrm{m}$ fines and secondly supplementing GB cement with a typical amount of fines.

In the first approach the cement was substituted with excessive amount $(80 \mathrm{~g})$ of fines in each $4 \mathrm{~kg}$ of coarse RC Aggregate test specimens. The GB cement was only used to devise a calibration curve. Figure 6 shows the calibration curve and an increase in temperature due to accelerated hydration of the aggregate's fines.

The results clearly indicate that solid cement paste residue in the aggregate combined with very fine particles cause a temperature rise, which is characteristic of the hydration of cements. An inclusion of $2 \%$ of particles smaller than $75 \mu \mathrm{m}$ appears to be the equivalent of approximately $0.57 \%$ of GB cement.

In the second approach where test specimens contained small amounts of GB cement $(0.5 \%, 1 \%$ and $1.5 \%)$, the average difference between hydration temperatures generated in basalt aggregate was lower by $1 \%$ compared with the temperature increase in the RC Aggregate. The additional heat generation is attributed to re-cementing properties of the fines. Test results indicate that to achieve the same heat of hydration, $1 \%$ of GB cement has to be added to natural aggregate and only $0.8 \%$ of GB cement needs to be added to RC Aggregate.

More extensive studies using XRD and methodology similar to that described in this section are currently being undertaken to further investigate the influence of cement paste residue on chemical bonding in concrete made from RC Aggregate. 


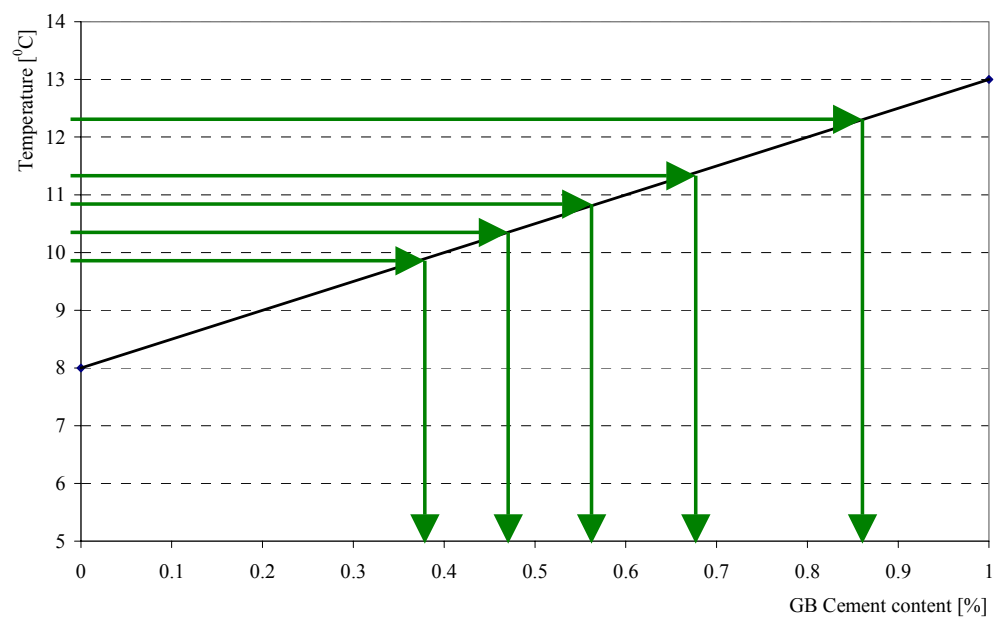

Figure 6: Equivalent GB cement content in RC Aggregate.

\section{Discussion}

Recycled concrete products contain significant amounts of cement paste residue, which are in a form of a very fine powder. The mineralogical composition of the very fine particles is different from commonly used natural aggregate in concrete production or aggregate used in road construction. The fines are calcium rich and have potential to augment hydration of cement.

Preliminary results indicate that re-cementing potential of RC Aggregate is equivalent to approximately $0.2 \%$ to $0.5 \%$ of general blended cement.

\section{Acknowledgement}

The authors would like to acknowledge the contributions of Mr. Hans Brinkies and Mrs. Savithri Galappathie.

\section{References}

[1] EcoRecycle Victoria, (2004). C\&D Waste 2004 Construction and Demolition Waste, EcoRecycle Victoria, http://www.ecorecycle. vic.gov.au viewed 2 November 2005

[2] Vicroads, (1997). Standard Specification for Roadwork and Bridgeworks - Section 820, Crushed concrete for pavement sub-base, Melbourne

[3] Krezel, Z.A., and McManus, K.J., (2001). New Products made from Concrete Waste, $3^{\text {rd }}$ International Congress "Added Value and Recycling of Industrial Waste”, L’Aquila, 25-29 June, Italy 
[4] Katz, A., (2002). Treatments for the Improvement of Recycled Aggregate, Journal of Materials in Civil Engineering Vol. 16, No. 6, December 2004

[5] Standards Association of Australia, (1996). Methods for sampling and testing aggregate, Method 72: Cement content of cement stabilised materials, (AS1141.72-1996), Standards Australia, Homebush, NSW 